\title{
Breastfeeding rates and barriers: a report from the State of Qatar
}

This article was published in the following Dove Press journal:

International Journal of Women's Health

\section{Mohamed A Hendaus ${ }^{1-3}$ \\ Ahmed H Alhammadi ${ }^{1-3}$ \\ Shabina Khan' \\ Samar Osman' \\ Adiba Hamad ${ }^{1,2}$}

'Department of Pediatrics, Section of Academic General Pediatrics, Hamad General Corporation, Doha, Qatar; ${ }^{2}$ Department of Pediatrics, Section of Academic General Pediatrics, Sidra Medicine, Doha, Qatar; ${ }^{3}$ Department of Clinical Pediatrics, Weill-Cornell Medicine, Doha, Qatar
Correspondence: Mohamed A Hendaus Department of Pediatrics, Hamad Medical Corporation, Doha 3050, Qatar

Tel +974 44392239

Fax+974 44439 57।

Emailmhendaus@yahoo.com

\begin{abstract}
Objective: The aim of the study was to outline breastfeeding barriers faced by women residing in the State of Qatar.

Methods: A cross-sectional study through a telephone interview was conducted at Hamad Medical Corporation, the only tertiary care and accredited academic institution in the State of Qatar. Mothers of children born between the period of January 1, 2012 and December 31, 2012 in the State of Qatar were contacted.
\end{abstract}

Results: Of the total 840 mothers who were contacted for the telephone survey, 453 mothers agreed to be interviewed (response rate 53.9\%), while $364(43.3 \%$ ) did not answer the phone, and $21(2.5 \%)$ answered the phone but refused to participate in the study. The overall breastfeeding initiation rate among the mothers was $96.2 \%$, with $3.8 \%$ mothers reporting that they had never breastfed their baby. The percentage of mothers who exclusively breastfed their children in the first 6 months was $24.3 \%$. The most common barriers to breastfeeding as perceived by our participants were the following: perception of lack of sufficient breast milk after delivery (44\%), formula is easy to use and more available soon after birth (17.8\%), mom had to return to work (16.3\%), lack of adequate knowledge about breastfeeding $(6.5 \%)$, and the concept that the infant did not tolerate breast milk (4.9\%).

Conclusion: Exclusive breastfeeding barriers as perceived by women residing in the State of Qatar, a wealthy rapidly developing country, do not differ much from those in other nations. What varies are the tremendous medical resources and the easy and comfortable access to health care in our community. We plan to implement a nationwide campaign to establish a prenatal breastfeeding counseling visit for all expecting mothers.

Keywords: barrier, delineate, breastfeeding, Qatar

\section{Introduction}

Since the short- and long-term medical and neurodevelopmental benefits of breastfeeding are known, infant nutrition should be treated as a public health issue and not merely a lifestyle option. ${ }^{1}$ The advantages of breastfeeding to the infant and mother have been long recognized and are extensively unquestioned. The advantages are developmental, alimentary, emotional, economical, immunological, and social. ${ }^{2}$ The Academy of Breastfeeding Medicine, the American Academy of Pediatrics, and the World Health Organization recommend exclusive breastfeeding for the first 6 months of life. Exclusive breastfeeding infers that no other liquid or solid food (excluding medicines) is delivered to the infant. To allow mothers to set up and continue exclusive breastfeeding for 6 months, it is advised to initiate breastfeeding prior to the second hour of life, to give breast milk ad lib on demand, and to avoid bottles. ${ }^{3-5}$ Despite the great short- and long-term advantages of breastfeeding and the high costs and risks 
associated with infant formula, there is an obvious disparity between present practice and accepted recommendations. ${ }^{5}$

Moreover, and in spite of a great attempt to promote breastfeeding globally, data show that the exclusive breastfeeding among children under 6 months in developing countries increased only by approximately $6 \%$ (from $33 \%$ to $39 \%$ ) between 1995 and $2010 .^{6}$

Globally, barriers to initiating and sustaining of breastfeeding comprise of lack of counseling and support from health care providers, ${ }^{7,8}$ lack of prenatal knowledge about breastfeeding, ${ }^{9}$ maternal job, ${ }^{10,11}$ media depiction of formula feeding as normative, ${ }^{12}$ inadequacy of social and family support, ${ }^{13}$ and marketing advertisement of baby formulas. ${ }^{14,15}$

There is no data or studies that outline exclusive breastfeeding barriers in the State of Qatar. The aim of the study was to outline breastfeeding barriers faced by women residing in the State of Qatar. This study delivers data for future research and can be used in other countries with a goal of improving the sustainability of breastfeeding as recommended by international organizations. Consequently, the aim of this study was to create a project to implement a nationwide campaign to establish prenatal breastfeeding counseling for all expecting mothers.

\section{Materials and methods}

\section{Study design, period, setting, and participants}

The State of Qatar is a peninsula located in the Asian continent, and the latitude and longitude for the country are $25.3000^{\circ} \mathrm{N}$ and $51.5333^{\circ} \mathrm{E}$, respectively. Qatar borders Saudi Arabia by land, and the maritime boundaries include Bahrain, Iran, and the United Arab Emirates. ${ }^{16}$ The population of Qatar comprises of 2,415,588 individuals. ${ }^{17}$

A cross-sectional study through a telephone interview was conducted at Hamad Medical Corporation, the only tertiary care and accredited academic institution in the State of Qatar. Mothers of children born between the period of January 1, 2012 and December 31, 2012 in the State of Qatar were contacted. Contact numbers were retrieved from the birth registry. A convenient sample was chosen, and participants were selected randomly using simple random sampling technique through a computer approach. Mothers were contacted between the period of January 1, 2014 and June 1, 2015.

Verbal informed consent was sought at the time of the telephone conversation, and all materials were available in
English and Arabic. Mothers were informed as to why the information was being gathered and how it would be utilized. Before the start of filling in the questionnaire, a statement was read to mothers informing them that their input was voluntary, and we mentioned that their responses were confidential and anonymous. Participants did not receive any type of monetary or nonmonetary compensation for being involved in the study. This study was approved by Hamad Medical Corporation Medical Research Center with reference numbers 13277/13 and 13278/13.

The following infants were excluded: 1) infants whose mothers have infectious diseases especially human immunodeficiency virus; 2) infants with prematurity who were admitted to the neonatal intensive care unit and were not able to initiate breastfeeding; 3 ) infants with craniofacial abnormalities who were not able to breastfeed; 4) infants with any disease that prevented them from breastfeeding.

We used an anonymous modified interview-based assessment of breastfeeding practice, with some data obtained from published studies, ${ }^{18-23}$ and modified it to meet our participants culture.

The Medical Research Center in our organization validated the questionnaire that comprised of a total of 18 items (Supplementary material). The questions addressed parents and children demographics, duration of exclusive breastfeeding, length of total (exclusive + nonexclusive) breastfeeding, and barriers to breastfeeding as perceived by the participants.

\section{Statistical analysis}

Quantitative data values were shown as frequencies along with percentages and mean $\pm \mathrm{SD}$. Descriptive statistics were applied to abridge demographic and all additional features of the participants. Associations between 2 or more qualitative or categorical variables were assessed using $\chi^{2}$ test. Graphic presentations were used to streamline the display of results. A 2 -sided $P$-value $<0.05$ was statistically significant. All statistical analyses were managed using statistical package SPSS, version 19.0 (IBM Corporation, Armonk, NY, USA).

\section{Results}

Of the total 840 mothers that were contacted for the telephone survey, 453 mothers agreed to be interviewed (response rate $53.9 \%)$, while $364(43.3 \%)$ did not answer the phone, and $21(2.5 \%)$ answered the phone but refused to participate in the study. Moreover, 2 infants, whose mothers were contacted, had since died and so the mothers were not interviewed. 
The overall breastfeeding initiation rate among our mothers was $96.2 \%$, with $3.8 \%$ mothers admitting that they had never breastfed their baby. Moreover, $41.3 \%$ of the mothers initiated breastfeeding but stopped it before the baby reached 6 months of age. The percentage of mothers who exclusively breastfed their children in the first 6 months was $24.3 \%$, while $25.6 \%$ were giving breast milk along with formula at 6 months of age. Only a small fraction of the mothers $(4.8 \%)$ were breastfeeding to any extent by the child's first birthday (Figure 1).

The sociodemographic characteristics of the participating mothers were analyzed to see if they had any impact on ever breastfeeding (Table 1). The rate of breastfeeding initiation was comparable between nationals and nonnationals (94.1\% [159/169] vs $98.2 \%$ [279/284]), $P$-value $=0.017$. Qatari women were less likely to exclusively breastfeed till 6 months of age when compared to their expatriate counterparts $(13.6 \%$ [23/169] vs $31.7 \%$ [90/284]), $P$-value $=0.0001$. They were also less likely to maintain any breastfeeding till 12 months of age (2.4\% [4/169] vs $6.3 \%$ [18/284]). However, the results were not statistically significant, $P$-value $=0.057$.

With regard to the mother's educational status, a higher educational level correlated positively with rates of ever breastfeeding. In addition, 97.7\% (379/388) of moms who had a secondary school education or a college degree initiated breastfeeding as compared to $86.4 \%$ (51/59) of moms who attended only primary school or were not schooled at all, $P$-value $=0.0001$. In contrast, paternal education did not seem to influence breastfeeding initiation rates as much. For instance, $96.5 \%(55 / 57)$ of women wed to fathers with no or primary schooling ever breastfed vs $92.9 \%$ (368/396) in women married to spouses who attended either secondary school or possessed a college degree, $P$-value $=0.314$. Interestingly, it was the father's and not the mother's age that was found to affect the breastfeeding initiation rate. Babies whose fathers were 40 years or older were less likely to be breastfed as compared to babies with younger fathers $(89.6 \%$ [69/77] vs $97.3 \%$ [357/367]), $P$-value $=0.002$.

Our study revealed that the rate of ever breastfeeding in the low birth weight infants (birth weight $<2.5 \mathrm{~kg}$ ), preterm infants ( $<37$ weeks), and babies admitted to the neonatal intensive care unit regardless of gestational age was $100 \%$.

The most common barriers to breastfeeding as perceived by our participants were as follows: perception of lack of sufficient breast milk after delivery (44\%), formula is easy to use and more available soon after birth (17.8\%), mom had to return to work (16.3\%), lack of adequate knowledge about breastfeeding (6.5\%), and the concept that the infant did not tolerate breast milk (4.9\%). Other reasons stated were cracked nipples, mastitis, difficulty breastfeeding with twins, mom got pregnant while breastfeeding, mom was on medications (nonspecific), a fear that breastfeeding causes unappealing changes in breast shape, and mom went for religious Hajj pilgrimage or resumed her college education.

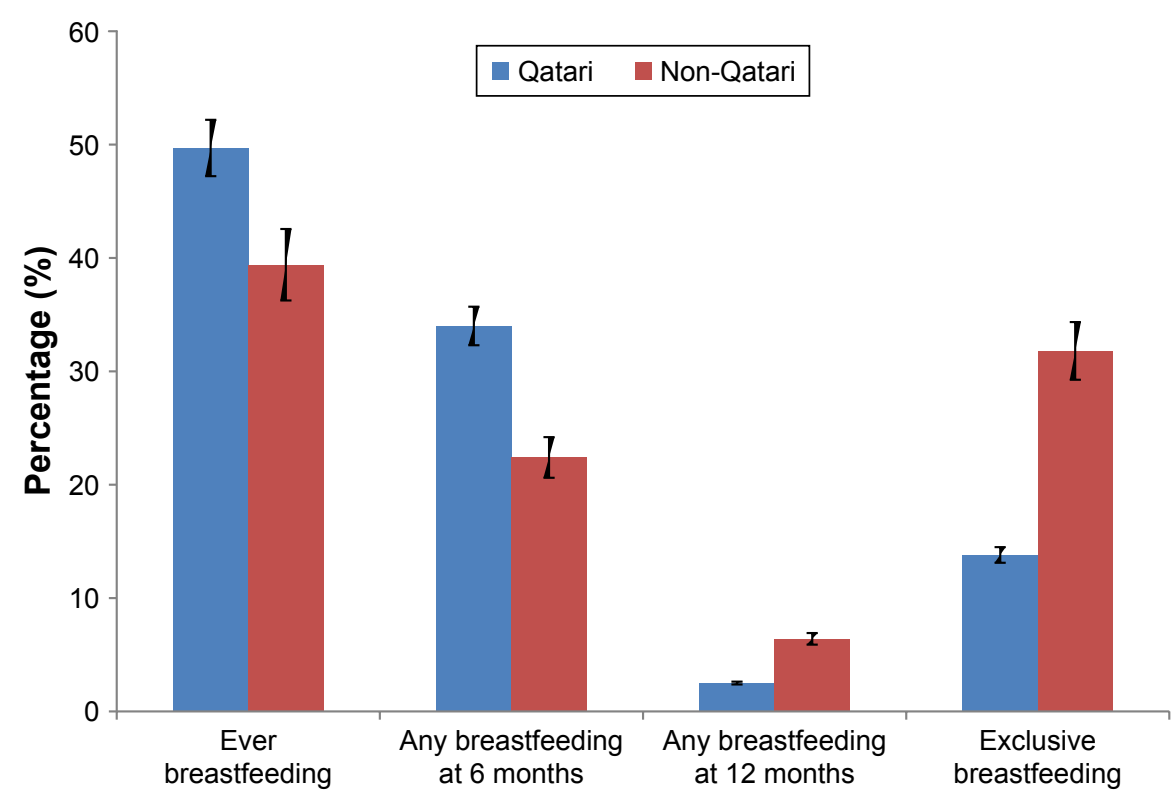

Figure I Any and exclusive breastfeeding. 
Table I Demographics

\begin{tabular}{|c|c|c|}
\hline Characteristics & $\begin{array}{l}\text { Sample } \\
\text { size }\end{array}$ & $\begin{array}{l}\text { Ever } \\
\text { breastfed (\%) }\end{array}$ \\
\hline Overall & 453 & 96.2 \\
\hline \multicolumn{3}{|l|}{ Infants gender } \\
\hline Male & 239 & 96.2 \\
\hline Female & 214 & 96.3 \\
\hline \multicolumn{3}{|l|}{ Birth order } \\
\hline First & 177 & 96.0 \\
\hline Second & 133 & 95.5 \\
\hline Third & 83 & 96.4 \\
\hline Fourth & 58 & 98.3 \\
\hline \multicolumn{3}{|l|}{ Type of delivery } \\
\hline Normal vaginal delivery & 320 & 96.3 \\
\hline Cesarean section & $|3|$ & 96.2 \\
\hline \multicolumn{3}{|l|}{ Gestational age } \\
\hline$<37$ weeks & 24 & 100 \\
\hline 37 weeks and above & 425 & 96.7 \\
\hline \multicolumn{3}{|l|}{ Birth weight } \\
\hline Below $2.5 \mathrm{~kg}$ & 22 & 100 \\
\hline $2.5-4 \mathrm{~kg}$ & 402 & 96.5 \\
\hline More than $4 \mathrm{~kg}$ & 28 & 89.3 \\
\hline \multicolumn{3}{|l|}{ Mother's age } \\
\hline$<20$ years & II & 100 \\
\hline $20-29$ years & 229 & 96.5 \\
\hline 30-39 years & 184 & 96.7 \\
\hline $40-49$ years & 24 & 87.5 \\
\hline \multicolumn{3}{|l|}{ Mother's education } \\
\hline Primary & 41 & 82.9 \\
\hline Secondary & 148 & 97.3 \\
\hline College/university & 240 & 98.3 \\
\hline No schooling & 18 & 88.9 \\
\hline \multicolumn{3}{|l|}{ Mother's working status } \\
\hline Working & 203 & 97.5 \\
\hline Housewife & 250 & 95.2 \\
\hline \multicolumn{3}{|c|}{ Does your work support breastfeeding? } \\
\hline Yes & 171 & 97.7 \\
\hline No & 32 & 96.9 \\
\hline \multicolumn{3}{|c|}{ Father's age at the time of birth } \\
\hline 20-29 years & 109 & 96.3 \\
\hline $30-39$ years & 258 & 98.1 \\
\hline $40-49$ years & 77 & 89.6 \\
\hline \multicolumn{3}{|l|}{ Father's education } \\
\hline Primary & 42 & 85.7 \\
\hline Secondary & 125 & 95.2 \\
\hline College/university & 271 & 98.2 \\
\hline No schooling & 15 & 100 \\
\hline \multicolumn{3}{|l|}{ Nationality } \\
\hline Qatari & 169 & 94.1 \\
\hline Other Arab countries & 153 & 96.7 \\
\hline African & 41 & 100 \\
\hline Indian subcontinent & 64 & 96.9 \\
\hline Others & 26 & 100 \\
\hline \multicolumn{3}{|c|}{$\begin{array}{l}\text { Was the baby admitted to the NICU } \\
\text { after delivery? }\end{array}$} \\
\hline Yes & 29 & 100 \\
\hline No & 424 & 96.0 \\
\hline
\end{tabular}

Abbreviation: NICU, neonatal intensive care unit.
The percentage (\%) of participants who had reported at least 1 barrier was 325/453=71.7\%; 2 barriers: 147/453=32.5\% and 3 barriers: $92 / 453=20.3 \%$ (112 women reported no barriers, while 11 refused to comment on the obstacles of breastfeeding).

\section{Discussion}

The contact information for the mothers was obtained from our hospital birth registry database. This information has been added to the methods section of the abstract. The number of births in the State of Qatar (including babies born abroad) was 21,769 in the year 2012. ${ }^{4}$

Our study has shown that the breastfeeding initiation rate in the State of Qatar started with a staggering and encouraging rate of $96.2 \%$. Unfortunately, by the time the infant was 6 months old, only $24.3 \%$ of these were still breastfeeding exclusively.

Breastfeeding practice differs among countries. For instance, breastfeeding up to 2 years is a common practice in Africa, while timely introduction of breast milk is highest in Latin America. ${ }^{25}$ Prevalence of exclusive breastfeeding as recommended by the World Health Organization has increased in developing countries from 33\% in 1995 to 39\% in 2010, with the vastest upgrading seen in West and Central Africa (increased from $12 \%$ in 1995 to $28 \%$ in 2010). ${ }^{6}$ However, countries in the Pacific and East Asia, which customarily have had high breastfeeding rates, ${ }^{26}$ have shown a decline in exclusive breastfeeding by $29 \%$ in $2012 .{ }^{27}$

Overall, there is a robust association between early cessation of breastfeeding and modernity. ${ }^{28}$ Breastfeeding rates might be determined by the level of health education particularly or by more general degree of schooling among parents. ${ }^{29}$ Breastfeeding behavior is driven by several cultural, social, and psychological factors apart from the availability of infant formula.

Low-income and rural households initiate breastfeeding late but continue longer. ${ }^{30} \mathrm{In}$ some cultures, exclusive breastfeeding is considered harmful to the infant. For instance, colostrum is usually thrown away because it is considered not clean, as perceived by a rural community in Nigeria. ${ }^{31}$ Some women are plainly physically incapable to produce sufficient breast milk, and hence infant formula is crucial; others merely may encounter hardship with the process, and therefore, health care providers play crucial roles in advocating and guiding new mothers about proper breastfeeding. ${ }^{30}$

Regrettably, not all health care providers are acquainted with breastfeeding, and some even endorse infant formula. ${ }^{26,30}$ 
Moreover, some physicians lack motivation to educate mothers because of the extra time commitment needed. ${ }^{32}$

Despite being safe and free, the process of breastfeeding has been perceived as time consuming and therefore less well-matched with modernity. ${ }^{33}$

Labor force circumstances and labor laws protecting women also affect breastfeeding attitudes. ${ }^{28} \mathrm{Chen}$ et $\mathrm{al}^{34}$ investigated the effects of work-related factors on the breastfeeding behavior of working mothers in a Taiwanese semiconductor manufacturer. The study which included 998 participants showed that only $10 \%$ of new mothers sustained in providing breast milk to their infants, mainly attributed to the inconvenient working setting for breastfeeding. The International Labor Organization has supported maternity leave and a family-friendly strategy given existing circumstances, as they are not favorable to a mother and child's wellbeing. Notwithstanding the International Labor Organization campaign, maternity lawmaking and laws caring for women are not always very robust in the developing world. ${ }^{35}$

Despite organized precautions, the literature stipulates evidence of sustained infant formula dissemination among breastfeeding women, and deficiency of breastfeeding education among mothers. ${ }^{36}$ Winikoff and Laukaran ${ }^{37}$ investigated infant feeding practices and their determinants in Thailand, Colombia, Kenya, and Indonesia, the 4 being considered developing countries. The study portrayed the advent of 4 beliefs: mothers believe they have inadequate milk, mothers believe infant formula is a practical substitute, mothers are aware about different brands of infant formula, and mothers are swayed to bottle-feed though the peer effect via family and friends.

A major breastfeeding barrier in our breastfeeding mothers was the perception of lack of sufficient breast milk after delivery.

Many new mothers discontinue breastfeeding during the initial weeks of the postpartum period because of perceived insufficient milk and nearly $35 \%$ of all women who discontinue breastfeeding early report perceived insufficient milk as the main reason. Several women use infant satisfaction innuendos as their main sign of milk supply. ${ }^{38}$

This perception of insufficient milk can often stem from a lack of confidence in mom's ability to breastfeed or inadequate knowledge about breastfeeding in general. ${ }^{39,40}$ Mothers can also experience an actual lack of milk supply because of ineffectual breastfeeding technique or because they are not feeding the baby often enough. ${ }^{41-43}$
Apparently, income does not affect the perception of insufficient milk. A study conducted in southwest Nigeria showed that a large proportion of women living at the poverty level or below believe that their breast milk does not suffice. ${ }^{44}$ Eventually, new mothers may opt to supplement breastfeeding with infant formula or other materials as a nutrition supporter to breast milk. However, this blending of breast milk with other materials through chemical reactions can diminish breast milk quality and curb duration of breastfeeding. ${ }^{26}$

Another major obstacle portrayed by our participants was lack of adequate knowledge about breastfeeding. The literature has shown that mothers believe that breast milk is optimal for their babies, but they lack knowledge about the specific declines in health risks that happen through the process of breastfeeding and the utilization of breast milk. Due to the inadequacy of this information, new moms cannot accurately distinguish the difference between breastfeeding vs formula feeding. ${ }^{45}$ Prenatal classes can be useful in providing education and counseling to women about the health benefits of breastfeeding, both for babies and mothers, and coaches can demonstrate to women the breastfeeding process and techniques. ${ }^{46}$ Moreover, expectant moms who perceive breastfeeding as hard or tedious recognize the fear of discomfort as a considerable negative influence on their devotion to initiate breastfeeding. ${ }^{47-50}$

Returning to work was another hurdle expressed by our mothers. The breastfeeding initiation rate in our participants was higher compared to other studies, ${ }^{51,52}$ but there was no major difference in the duration. ${ }^{22,51,53,54}$

Published studies have shown that the rates of breastfeeding initiation and duration are greater in mothers who have extended maternity leave, ${ }^{22,46,53-56}$ those who have breastfeeding encouragement programs where they work, ${ }^{57,58}$ and those who work part-time instead of full-time..$^{52,54,59}$ Pumping breast milk to be administered to infants by care givers while mom is at work seems to be a good idea, but the literature has shown that it is the process of natural skin to skin contact that boosts the duration and the ferocity of breastfeeding. ${ }^{60,61}$

These findings will allow us to propose a comprehensive national prenatal visit to educate future mothers of the advantages of breastfeeding as well as provide them with evidencebased medicine instead of counting on perceptions to sustain exclusive breastfeeding for at least 6 months. Lamentably, these attempts are few and inadequate nationwide; hence, there is an need for physicians, including pediatricians, to greatly contribute in breastfeeding counseling. We believe 
that this target is reachable due to the tremendous medical resources and the easy and comfortable access to health care in the State of Qatar.

This study has limitations. For instance, we used a convenience sample, and therefore we are planning to conduct this study again using a larger sample as well as including several hospitals for better generalization. In addition, a recall bias could have influenced the responses. Moreover, there might be a possibility that there are specific characteristics related to breastfeeding prevalence and barriers that were not appraised in this study.

\section{Conclusion}

Exclusive breastfeeding barriers as perceived by women residing in the State of Qatar, a wealthy rapidly developing country, do not differ much from those in other nations. What varies are the tremendous medical resources and the easy and comfortable access to health care in our community. We plan to implement a nationwide campaign to establish a prenatal breastfeeding counseling visit for all expecting mothers.

\section{Ethics approval}

Hamad Medical Corporation-Ethics Committee (Ref \#13277/13 and 13278/13).

\section{Acknowledgment}

The authors would like to thank the Medical Research center in Hamad Medical Corporation for their support and ethical approval. Data from the earlier stages of the study were presented in the 2015 American Academy of Pediatrics National Conference \& Exhibition.

\section{Disclosure}

The authors report no conflicts of interest in this work.

\section{References}

1. Section on Breastfeeding. Breastfeeding and the use of human milk. Pediatrics. 2012;129(3):e827-e841.

2. Earle S. Factors affecting the initiation of breastfeeding: implications for breastfeeding promotion. Health Promot Int. 2002;17(3):205-214.

3. Chantry CJ, Eglash A, Labbok M. ABM Position on BreastfeedingRevised 2015. Breastfeed Med. 2015;10(9):407-411.

4. American Academy of Pediatrics, Work Group on Breastfeeding. Breastfeeding and the use of human milk. Pediatrics. 1997;100:1035-1039.

5. World Health Organization (WHO). Breastfeeding. Geneva: World Health Organization. Available from: http://www.who.int/maternal_ child_adolescent/topics/newborn/nutrition/breastfeeding/en/. Accessed December 1, 2016.

6. Cai X, Wardlaw T, Brown DW. Global trends in exclusive breastfeeding. Int Breastfeed J. 2012;7(1):12.

7. Williams EL, Hammer LD. Breastfeeding attitudes and knowledge of pediatricians-in-training. Am J Prev Med. 1995;11(1):26-33.

8. Freed GL, Jones TM, Fraley JK. Attitudes and education of pediatric house staff concerning breast-feeding. South Med J. 1992;85(5): 483-485.
9. World Health Organization and United Nations Children's Fund. Protecting, Promoting and Supporting Breast-Feeding: The Special Role of Maternity Services. Geneva, Switzerland: World Health Organization; 1989:13-18.

10. Ryan AS, Martinez GA. Breast-feeding and the working mother: a profile. Pediatrics. 1989;83(4):524-531.

11. Gielen AC, Faden RR, O'Campo P, Brown CH, Paige DM. Maternal employment during the early postpartum period: effects on initiation and continuation of breast-feeding. Pediatrics. 1991;87(3):298-305.

12. World Health Assembly. International Code of Marketing of Breast-Milk Substitutes. Resolution of the 34th World Health Assembly No. 34.22. Geneva, Switzerland: World Health Organization; 1981. Available from: http://www.who.int/nutrition/publications/code_english.pdf

13. Brand E, Kothari C, Stark MA. Factors related to breastfeeding discontinuation between hospital discharge and 2 weeks postpartum. J Perinat Educ. 2011;20(1):36-44.

14. Kaplan DL, Graff KM. Marketing breastfeeding - reversing corporate influence on infant feeding practices. J Urban Health. 2008; 85(4):486-504.

15. Howard CR, Howard FM, Weitzman ML. Infant formula distribution and advertising in pregnancy: a hospital survey. Birth. 1994;21(1):14-19.

16. Where is Qatar? Available from: http://www.mapsofworld.com/qatar/ qatar-location-inworld-map.html. Accessed July 8, 2015.

17. Qatar Population. Countrymeters. Available from: http://countrymeters. info/en/Qatar. Accessed January 27, 2017.

18. Foo LL, Quek SJ, Ng SA, Lim MT, Deurenberg-Yap M. Breastfeeding prevalence and practices among Singaporean Chinese, Malay and Indian mothers. Health Promot Int. 2005;20(3):229-237.

19. Li R, Zhao Z, Mokdad A, Barker L, Grummer-Strawn L. Prevalence of breastfeeding in the United States: the 2001 National Immunization Survey. Pediatrics. 2003;111(5 Pt 2):1198-1201.

20. Nkala TE, Msuya SE. Prevalence and predictors of exclusive breastfeeding among women in Kigoma region, Western Tanzania: a community based cross-sectional study. Int Breastfeed J. 2011;6(1):17.

21. Häggkvist AP, Brantsæter AL, Grjibovski AM, Helsing E, Meltzer HM, Haugen M. Prevalence of breast-feeding in the Norwegian Mother and Child Cohort Study and health service-related correlates of cessation of full breast-feeding. Public Health Nutr. 2010;13(12):2076-2086.

22. Li R, Darling N, Maurice E, Barker L, Grummer-Strawn LM. Breastfeeding rates in the United States by characteristics of the child, mother, or family: the 2002 National Immunization Survey. Pediatrics. 2005; 115(1):e31-e37.

23. Saied H, Mohamed A, Suliman A, Al Anazi W. Breastfeeding knowledge, attitude and barriers among Saudi women in Riyadh. J Nat Sci Res. 2013;3(12):6-133.

24. Ministry of Development Planning and Statistics. Births and Deaths in the State of Qatar. Doha, Qatar: Ministry of Development Planning and Statistics; 2017. Available from: https://www.mdps.gov.qa/ en/statistics/Statistical\%20Releases/Population/BirthsDeaths/2015/ birth_death_2015_EN.pdf. Accessed March 4, 2018.

25. Black RE, Victora CG, Walker SP, et al; Maternal and Child Nutrition Study Group. Maternal and child undernutrition and overweight in low-income and middle-income countries. Lancet. 2013;382(9890): 427-451.

26. Barennes H, Empis G, Quang TD, et al. Breast-milk substitutes: a new old-threat for breastfeeding policy in developing countries. A case study in a traditionally high breastfeeding country. PLoS One. 2012; 7(2):e30634.

27. UNICEF. The State of the World's Children 2012. Children in an Urban World. New York: UNICEF. Available from: https://www. unicef.org/sowc2012/pdfs/SOWC\%202012-Executive\%20Summary_EN_13Mar2012.pdf. Accessed August 13, 2018.

28. Abada TS, Trovato F, Lalu N. Determinants of breastfeeding in the Philippines: a survival analysis. Soc Sci Med. 2001;52(1):71-81.

29. Heck KE, Braveman P, Cubbin C, Chávez GF, Kiely JL. Socioeconomic status and breastfeeding initiation among California mothers. Public Health Rep. 2006;121(1):51-59. 
30. Save the Children. Superfood for Babies. How Overcoming Barriers to Breastfeeding will Save Children's Lives. London: Save the Children. Available from: https://www.savethechildren.org/content/dam/global/ reports/health-and-nutrition/baby-superfood-asia.pdf?vanityurl=BFReport. Accessed August 13, 2018.

31. Davies-Adetugbo AA. Sociocultural factors and the promotion of exclusive breastfeeding in rural Yoruba communities of Osun State, Nigeria. Soc Sci Med. 1997;45(1):113-125.

32. Poduval J, Poduval M. Working mothers: how much working, how much mothers, and where is the womanhood? Mens Sana Monogr. 2009;7(1):63-79.

33. Noonan MC, Rippeyoung PL. The economic costs of breastfeeding for women. Breastfeed Med. 2011;6:325-327.

34. Chen YC, Wu YC, Chie WC. Effects of work-related factors on the breastfeeding behavior of working mothers in a Taiwanese semiconductor manufacturer: a cross-sectional survey. BMC Public Health. 2006;6:160.

35. Addati L, Cassirer N, Gilchrist K. Maternity and Paternity at Work: Law and Practice Across the World. Geneva: International Labour Office 2014. Available from: http:/www.ilo.org/wcmsp5/groups/public/--dgreports/---dcomm/---publ/documents/publication/wcms_242615. pdf. Accessed August 13, 2018.

36. Stuebe A. The risks of not breastfeeding for mothers and infants. Rev Obstet Gynecol. 2009;2(4):222-231.

37. Winikoff B, Laukaran VH. Breast feeding and bottle feeding controversies in the developing world: evidence from a study in 4 countries. Soc Sci Med. 1989;29(7):859-868.

38. Gatti L. Maternal perceptions of insufficient milk supply in breastfeeding. J Nurs Scholarsh. 2008;40(4):355-363.

39. Powers NG. Slow weight gain and low milk supply in the breastfeeding dyad. Clin Perinatol. 1999;26(2):399-430.

40. Dykes F, Williams C. Falling by the wayside: a phenomenological exploration of perceived breast-milk inadequacy in lactating women. Midwifery. 1999;15(4):232-246.

41. Dewey KG, Heinig MJ, Nommsen LA, Lönnerdal B. Adequacy of energy intake among breast-fed infants in the DARLING study: relationships to growth velocity, morbidity, and activity levels. Davis Area Research on Lactation, Infant Nutrition and Growth. J Pediatr. 1991;119(4):538-547.

42. Amir LH. Breastfeeding - managing "supply" difficulties. Aust Fam Physician. 2006;35(9):686-689.

43. Neville MC, Keller R, Seacat J, et al. Studies in human lactation: milk volumes in lactating women during the onset of lactation and full lactation. Am J Clin Nutr. 1988;48(6):1375-1386.

44. Agunbiade OM, Ogunleye OV. Constraints to exclusive breastfeeding practice among breastfeeding mothers in Southwest Nigeria: implications for scaling up. Int Breastfeed J. 2012;7:5.
45. McCann MF, Baydar N, Williams RL. Breastfeeding attitudes and reported problems in a national sample of WIC participants. J Hum Lact. 2007;23(4):314-324.

46. US Preventive Services Task Force. Primary care interventions to promote breastfeeding: US Preventive Services Task Force recommendation statement. Ann Intern Med. 2008;149(8):560-564.

47. Gill SL, Reifsnider E, Mann AR, Villarreal P, Tinkle MB. Assessing infant breastfeeding beliefs among low-income Mexican Americans. J Perinat Educ. 2004;13(3):39-50.

48. Libbus K, Bush TA, Hockman NM. Breastfeeding beliefs of low-income primigravidae. Int J Nurs Stud. 1997;34(2):144-150.

49. Bunik M, Clark L, Zimmer LM, et al. Early infant feeding decisions in low-income Latinas. Breastfeed Med. 2006;1(4):225-235.

50. Anderson AS, Guthrie CA, Alder EM, Forsyth S, Howie PW, Williams FL. Rattling the plate - reasons and rationales for early weaning. Health Educ Res. 2001;16(4):471-479.

51. Chatterji P, Frick KD. Does returning to work after childbirth affect breastfeeding practices? Rev Econ Househ. 2005;3(3):315-335.

52. Mandal B, Roe BE, Fein SB. The differential effects of full-time and parttime work status on breastfeeding. Health Policy. 2010;97(1):79-86.

53. Guendelman S, Kosa JL, Pearl M, Graham S, Goodman J, Kharrazi M Juggling work and breastfeeding: effects of maternity leave and occupational characteristics. Pediatrics. 2009;123(1):e38-e46.

54. Ryan AS, Zhou W, Arensberg MB. The effect of employment status on breastfeeding in the United States. Womens Health Issues. 2006;16(5): 243-251.

55. Visness CM, Kennedy KI. Maternal employment and breast-feeding: findings from the 1988 National Maternal and Infant Health Survey. Am J Public Health. 1997;87(6):945-950.

56. Lindberg LD. Trends in the relationship between breastfeeding and postpartum employment in the United States. Soc Biol. 1996;43(3-4): 191-202.

57. Whaley SE, Meehan K, Lange L, Slusser W, Jenks E. Predictors of breastfeeding duration for employees of the Special Supplemental Nutrition Program for Women, Infants, and Children (WIC). J Am Diet Assoc. 2002;102(9):1290-1293.

58. Ortiz J, McGilligan K, Kelly P. Duration of breast milk expression among working mothers enrolled in an employer-sponsored lactation program. Pediatr Nurs. 2004;30(2):111-119.

59. Berger LM, Hill J, Waldfogel J. Maternity leave, early maternal employment and child health and development in the US. Econ J. 2005; 115(501):F29-F47.

60. Fein SB, Labiner-Wolfe J, Shealy KR, Li R, Chen J, Grummer-Strawn LM. Infant Feeding Practices Study II: study methods. Pediatrics. 2008; 122(Supp1 2):S28-S35.

61. Fein SB, Mandal B, Roe BE. Success of strategies for combining employment and breastfeeding. Pediatrics. 2008;122(Suppl 2):S56-S62. 


\section{Supplementary material}

\begin{tabular}{|c|c|}
\hline Child demographic & Family demographic \\
\hline$\underline{\text { Sex: }}$ & Age of mother (in years) at time of birth: \\
\hline$\square$ Male & $\square 19$ years and below \\
\hline$\square$ Female & $\square$ 20-29 years \\
\hline Birth ordor. & $\square$ 30-39 years \\
\hline Birth order: & $\square$ 40-49 years \\
\hline$\square$ Second & Mother education: \\
\hline$\square$ Third & $\square$ Primary \\
\hline$\square$ Fourth & $\square$ Secondary \\
\hline$\square$ Other & $\square$ College and above \\
\hline Type of deliverv: & $\square$ No schooling \\
\hline$\square$ Normal vaginal delivery & Mother's working status: \\
\hline$\square$ C-section & $\square$ Working \\
\hline Gestational age & $\square$ Housewife \\
\hline$\square$ Full term & Does your work support breastfeeding practice? \\
\hline$\square$ Preterm/premature & $\square$ Yes \\
\hline Birth weight: & $\square$ No \\
\hline Birth weight: & $\square$ I do not know \\
\hline Was your baby admitted to the Neonatal Intensive & Father's age: \\
\hline Care Unit (NICU)? & \\
\hline$\square$ Yes & Father education: \\
\hline$\square$ No & $\square$ Primary \\
\hline & $\square$ Secondary \\
\hline & $\square$ College and above \\
\hline & Nationality \\
\hline & $\square$ Qatari \\
\hline & $\square$ Other Arab Countries \\
\hline & $\square$ African \\
\hline & $\square$ Indian subcontinent \\
\hline & $\square$ Other Nationalities \\
\hline
\end{tabular}

\section{Which food was given first after birth?}

$\square$ breast milk, $\square$ glucose water, $\square$ formula milk, $\square$ others

Have you breastfed?

$\square$ yes $\square$ no

\section{If yes,}

For how long was your child exclusively breastfed (months)?

$\square$ Less than one month $\square$ one month $\square$ two months $\square$ three months $\square 4$ months $\square 5$ months $\square 6$ months $\square$ more than six months

At what age you introduced milk or food other than breast milk

$\square$ Less than one month $\square$ one month $\square$ two months $\square$ three months $\square 4$ months $\square 5$ months $\square 6$ months

$\square$ more than six months 
Conclusion (Breastfeeding):

$\square$ ever breastfeeding

$\square$ any breastfeeding

$\square$ any breastfeeding at 12 month

$\square$ exclusive breastfeeding

What do you think is the reason that you did not initiate or continued exclusive breastfeeding? (Answer one or more)

$\square$ Formula is easy to use and more available soon after birth

$\square$ Lack of adequate knowledge about breastfeeding

$\square$ Breastfeeding will not provide enough milk

Breastfeeding causes unappealing changes in breast shape

$\square$ Formula contains more nutritional value than breast milk

Return to work

$\square$ Other reasons:

\section{Other comments:}

\section{Publish your work in this journal}

The International Journal of Women's Health is an international, peerreviewed open-access journal publishing original research, reports, editorials, reviews and commentaries on all aspects of women's healthcare including gynecology, obstetrics, and breast cancer. The manuscript management system is completely online and includes a very quick and fair peer-review system, which is all easy to use. Visit http://www.dovepress.com/testimonials.php to read real quotes from published authors. 